\title{
HORAS “IN ITINERE" E A HIPOSSUFICIÊNCIA DO TRABALHADOR RURAL NA REFORMA TRABALHISTA.
}

\author{
Clarissa Manzano Dos Santos Falconi \\ E-mail: clarissamanzano@hotmail.com
}

\begin{abstract}
RESUMO
O presente trabalho versou sobre os impactos da Reforma Trabalhista nas horas "in itinere" para o trabalhador rural, com o objetivo de demonstrar a falta de representatividade destes trabalhadores no processo legislativo e sua hipossuficiência perante empregadores e Estado, tendo como resultado a análise dos perfis dos congressistas das bancadas ruralistas e seus interesses partidários e do trabalhador rural, tendo como método utilizado indutivo e hipotéticodedutivo e concluindo-se pela discrepância entre os interesses dos trabalhadores e da classe política, fazendo necessária, no mínimo, uma representação que busque a proteção da dignidade humana e o princípio tutelar na elaboração dos projetos para a categoria.
\end{abstract}

Palavras chave: Reforma Trabalhista. Horas In Itinere. Trabalhador Rural.

HOURS "IN ITINERE" AND THE HYPOSSUFICIENCE OF THE RURAL WORKER IN THE REFORM WORKER.

\begin{abstract}
The present study deals with the impacts of the Labor Reform in the hours "in itinere" for the rural worker, with the objective of demonstrating the lack of representativeness of these workers in the legislative process and their hypersufficiency before employers and State, resulting in the analysis of the profiles of the congressmen of the ruralist groups and their party interests and the rural worker, using as an inductive and hypothetical-deductive method and concluding by the discrepancy between the interests of the workers and the political class, making at least a representation that seeks the protection of human dignity and the guiding principle in the design of projects for the category.
\end{abstract}

Keywords: Labor Reform. Hours In Itinere. Rural Worker. 


\section{INTRODUÇÃO}

Com a promulgação da Lei n 13.467/2017 - Reforma Trabalhista, a supressão das horas "in itinere", antes prevista no artigo 58 parágrafo segundo CLT e regulada pela súmula 90 do TST, afetou sensivelmente os salários dos empregados, em especial, os trabalhadores rurais.

Com a nova legislação, trabalhadores admitidos após a vigência da lei, datada de 11 de novembro de 2017, não terão direito à hora "in itinere", a não ser que venha ser posta em negociação coletiva.

O objetivo deste estudo foi demonstrar a crise de representatividade desta categoria, com fundamento no princípio protetor e em bases estatísticas das propostas legislativas de Frente Parlamentar Agropecuária contrárias aos seus interesses, fato que corrobora a hipossuficiência do obreiro frente a empregadores e Congresso.

\section{METODOLOGIA}

Foi utilizado o método indutivo, que parte da particularidade do trabalhador na terra para a sua participação democrática no processo legislativo de leis. Além desse método, o artigo apresenta enfoque no método hipotético-dedutivo, partindo do problema da representatividade dos trabalhadores rurais, buscando base teórica para essa ausência, com verificação de dados estatísticos e coleta de dados inerentes ao tema.

\section{RESULTADOS}

Perfil da bancada ruralista no Congresso conforme a organização não - governamental REPÚLICA DOS RURALISTAS, na sessão "Quem é Quem no Mundo Rural”, 2014:

Ivo Cassol: É senador pelo estado de Rondônia e representante da Bancada Ruralista no Congresso. Cassol é dono de uma grande fazenda na região do Rio Guaporé, numa área reivindicada como terra indígena pelo povo Wajuru.. Entre as mais de 18 citações na Justiça, Cassol responde à acusação de comandar um esquema de extração clandestina de diamantes e contrabando de ouro na reserva indígena Roosevelt, do povo Cinta Larga, em 2004. Declarou ao TSE ter um patrimônio de mais de 29 milhões de reais. O senador informou possuir $\mathrm{R} \$ 155.800,00$ no total em imóveis rurais em Rondônia. Além disso teve seu patrimônio quase dobrado de $\mathrm{R} \$ 15.407 .511,00$, declarado em 2006, ao apresentado em 2010. No cadastro do INCRA, em nome da Cassol Agropecuária LTDA, são sete imóveis que somam 7.730 hectares, todas localizadas em Santa Luzia do Oeste, sendo que seis propriedades foram declaradas propriedades improdutivas. Outra empresa encontrada no cadastro do INCRA é a Eletrosol Centrais Elétricas Cassol com 271 hectares, em Alta Floresta D'Oeste, e 175 hectares em Vilhena (RO). Financiamento de campanha: Recebeu Total de receitas declaradas nas eleições de 2010: $\mathrm{R} \$$ 7.924.244,43. Empresas doadoras: Distribuidora Equador de Produtos de Petróleo LTDA; Coimbra Importação e Exportação LTDA; Independência Alimentos LTDA; Mercantil Nova Era LTDA; Canaã Ind. Laticínio LTDA; Tapajós Com. Rep. LTDA; Ronsy Imp. e Exp. LTDA; Plano da Amazônia LTDA.

Nilson Leitão: Ligado à Frente Parlamentar da Agropecuária é também um dos autores do PLP 227/2012 e faz parte da comissão da PEC 215/2000. Votou a favor da alteração do Código Florestal (Lei 12.650/2012). Criador do PL PL 6442/2016 que muda a lei que regulamenta o trabalho no campo. Patrimônio total declarado: R\$ 554.243,91. Financiamento de campanha: em 2014 recebeu R\$ 200 mil do fazendeiro Wilson Roque Pozzobon, mais R\$ 94 mil de Erai Maggi, nomeado pela Revista Dinheiro Rural como "O Rei da Soja" e "O Rei do Boi". Dentre as principais empresas financiadoras de sua campanha está a Copersucar, maior exportadora brasileira de açúcar e etanol com R\$100 mil. No total recebeu $\mathrm{R} \$ \mathbf{8 7 9 . 5 8 4 , 2 5}$ e foi eleito. Alguns dos doadores da campanha de 2014:AB Milhomens ME, Copersucar Sa, CRBS SA, Erai Maggi Scheffer, WDP Armazens Gerais LTDA, Wilson Roque Pozzobon. 
Outra pesquisa, demonstra a contingência de trabalhadores, conforme pesquisa do Dieese (edição 74 de out. 2014):

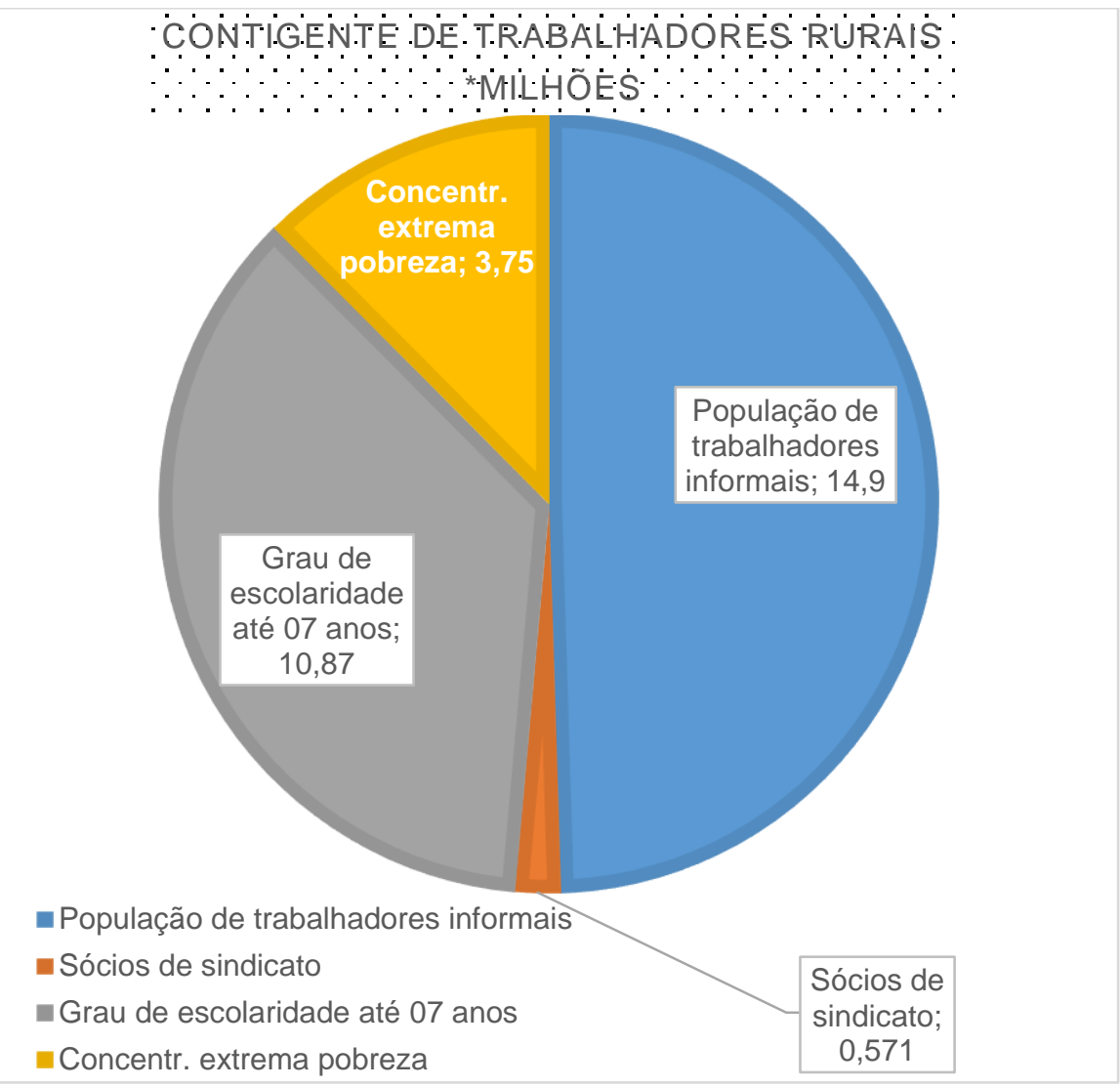

\section{DISCUSSÃO}

O princípio protetor no Direito do Trabalho consiste no uso da norma e da condição mais favorável ao trabalhador, de forma a buscar a igualdade material jurídica frente à condição de hipossuficiente do empregado.

É certo que o princípio protetor possui estes três desdobramentos. No entanto, o princípio protetor deve ser integrado a outros princípios da norma jurídica e sair da esfera princípio-norma para dar realização a sua finalidade principal de proteção ao obreiro.

Nesse horizonte, mencionamos DELGADO (2011, p. 193):

$\mathrm{Na}$ verdade, a noção de tutela obreira e de retificação jurídica da reconhecida desigualdade socioeconômica e de poder entre os sujeitos da relação de emprego (ideia inerente ao princípio protetor) não se desdobra apenas nas três citadas dimensões. Ela abrange, essencialmente, quase todos (senão todos) os princípios especiais de Direito Individual do Trabalho. [...] Todos [...] outros princípios especiais também criam, no âmbito de sua abrangência, uma proteção especial aos interesses contratuais obreiros [...].

Com o advento da Reforma Trabalhista, a supressão das horas "in itinere" definidas pelo artigo 58, parágrafo segundo da CLT afetou significativamente e, em especial, o trabalhador rural, excluído da essencialidade do princípio protetor pelo Legislativo e pelo Estado.

O obreiro rural, com base nas estatísticas do Dieese levantadas à priori, situa-se marginalizado da sociedade, pois: a maioria possui baixa escolaridade, fato que dificulta sua inserção na discussão legislativa e como ela pode agir como e a seu favor; entre a totalidade dos trabalhadores rurais, uma minoria é sindicalizada, como a Reforma atribuiu maior poder às 
negociações coletivas, 89 \% não possui amparo sindical, fato que leva a uma falta de representatividade nessas negociações; metade destes trabalhadores trabalha na informalidade, em regime de intermitência, contribuindo para um círculo vicioso de pobreza extrema, causando uma dependência de "quaisquer" condições de trabalho que sejam oferecidas.

Estima-se uma perda salarial entre $20 \%$ a $30 \%$ do salário com a supressão do deslocamento até o local de trabalho para trabalhadores admitidos com o advento da nova lei. É mister salientar que essa supressão pode ser mitigada por negociação coletiva, mas como essa negociação chegará aos não-sindicalizados, que constituem a grande maioria?

A hipossuficiência desta população é tão grande que a RAÍZEN, empresa do ramo de cana de açúcar, com faturamento estimado em $\mathrm{R} \$ \mathbf{8 6 , 2}$ bilhões, conforme informações retiradas do site da empresa em 2019,suprimiu do salário este adicional, assim que a lei entrou em vigor, aplicando-a indistintamente a trabalhadores novos e antigos, num afronto aos princípios da vedação do retrocesso social e da condição mais benéfica, sendo condenada em segunda instância pela atuação (PENHA, 2018, RAíZEN, 2018 e G1, 2018).

Além dessa hipossuficiência frente ao empregador, há uma hipossuficiência velada em relação à representatividade da categoria no Congresso Nacional.

Segundo o jornal Gazeta do Povo, a Bancada Ruralista do Congresso possui um extenso poder de votação, com estimativa de 209 deputados e 26 senadores, ora pertencentes a Frente Parlamentar Agropecuária, ora não pertencentes, mas ligados aos interesses do setor (ALVES,2018).

Ao associar que deputados e senadores ruralistas votam à favor da Reforma, que apoiam a PEC do deputado Nilson Leitão - a PEC estabelece o pagamento de salário por quaisquer meios de pagamento, entre outras mudanças negativas ao trabalhador rural - e à pressão que exercem para o PL 6299/02, chamada de "Proposta do Veneno", que diminui a restrição para produção e venda de agrotóxicos no Brasil, pergunta-se: a favor de quem há essa atuação? (TERRA, 2017).

Para a resposta, houve o cruzamento de dados de parlamentares da bancada, de grande influência política, e percebeu-se que: ora foram financiados por grandes empresas do setor agropecuário, incluindo o Grupo Maggi, de Blairo Maggi, atual Ministro da Agricultura no governo Temer; outros parlamentares são grandes proprietários de terra, destes, um investigado por contrabando em terras indígenas, outros por fazerem lobby contra a PEC do trabalho escravo PEC, esta que beneficiava trabalhadores rurais da região onde possuem propriedades (REVISTA GUIA DO ESTUDANTE, 2017).

Diante dessas informações, é a falta de protecionismo pelo Legislativo para atender a fenômenos complexos da precarização do trabalho rural que vai levar trabalhadores, além da redução de salários, a jornada de 18 dias seguidos, a manusear agrotóxicos lesivos à saúde e, em condições de extrema pobreza e marginalidade, abrir brechas para a troca de trabalho por comida, caso o PL de Nilson Leitão, líder da bancada ruralista no ano de 2017, siga adiante.

Com isso, ressalta-se a importância de uma efetiva proteção pelo Estado e pela sociedade para que esses interesses privados na elaboração de leis tenham limite, e que o Congresso atue não só para grandes empresas e latifundiários, mas também para a proteção da dignidade humana, base do princípio da proteção do trabalhador, incluindo-os na base de uma sociedade democrática. 


\section{CONCLUSÃO}

A supressão das horas "in itinere" é o exemplo mais preciso de como alianças partidárias podem e vão continuar a beneficiar seus financiadores de campanha, em prejuízo de um nicho criado à periferia dos direitos sociais básicos. É urgente uma atuação da sociedade, sindicatos e dos três poderes na proteção do trabalhador rural.

A falta de representatividade da categoria é clara e existe tanto na esfera sindical, quanto no congresso, este, resultante de interesses políticos específicos, amparados por grandes produtores e empresários do agronegócio. De outro lado, tem-se o trabalhador, hipossuficiente frente ao empregador, frente a direitos básicos e à mercê de leis que beiram o retrocesso social, análogas ao regime de escravidão que o Brasil tanto relutou em sair. Sem essa atuação conjunta, a Reforma será o princípio de outros projetos criados no silêncio da tribuna, em benefício de poucos e abastados cidadãos.

\section{REFERÊNCIAS}

ALVES, Débora. Jornal eletrônico Gazeta do Povo. Brasília, 02 de Jul. de 2018. Disponível em: https://www.gazetadopovo.com.br/politica/republica/como-o grupo-politico-mais-forte-do-paisconsegue-ganhar-todas-no-congresso-b1uw3×3c12qkpwusasdba00ej. Acesso em 02 de Ago. de 2018.

BRASIL. Lei № 13.467, de 13 de julho de 2017. Altera a Consolidação das Leis do Trabalho (CLT). Disponível em: http://www.planalto.gov.br/ccivil_03/_ato2015-2018/2017/lei/L13467.html . Acesso em 10 de Ago. de 2018.

DADOS dos Parlamentares em lista. Disponível em: http://www.republicadosruralistas.com.br/ruralistas. Acesso em 04 de Ago. de 2018.

DELGADO, Maurício Godinho. Curso de Direito do Trabalho. 4. ed. São Paulo: LTR, 2011.

Dieese, Org. Departamento intersindical de estatísticas e estudos econômicos. Número 74, Out. 2014.

Disponível

em:

https://www.dieese.org.br/estudosepesquisas/2014/estpesq74trabalhoRural.pdf. Acesso em : 14 de Jul. de 2018.

G1, São Paulo e Araraquara. 18 de Mai. De 2018. Disponível em https://g1.globo.com/sp/saocarlos-regiao/noticia/justica-determina-que-raizen-pague-horas-gastas-no-percurso-dostrabalhadores-ate-o-campo.ghtml. Acesso em 30 de Jul. de 2018.

PENHA, Daniela. Revista Eletrônica Repórter Brasil. 16 de Mai. 2018. Disponível em: http://reporterbrasil.org.br/2018/05/justica-determina-que-raizen-volte-a-pagar-horas-detransporte-aos-trabalhadores-de-araraquara.Acesso em 31 de Jul. de 2018.

PROPOSTA da bancada ruralista enfraquece fiscalizações no campo. 05 de Mai. 2017. Disponível em: https://www.terra.com.br/economia/a-reforma-que-sem-alarde-mira-o-trabalhadorrural,6b066ab3ccb5a70b42038e524cb70c6cafi9sbf4.html. Acesso em 16 de Ago. de 2018.

RAZEIN. Disponível em: https://www.raizen.com.br/sobre-raizen/raizen-em-numeros. Acesso em 05 de Ago. 2018. 
REVISTA Guia do Estudante. Ago. 2017. Disponível em: https://guiadoestudante.abril.com.br/blog/atualidades-vestibular/o-poder-da-bancada-ruralistano-congresso. Acesso em 11 Ago. 2018. 